\title{
LA DIALÉCTICA SOCIAL EN GURVITCH Y SARTRE
}

Hay dos opiniones prevalecientes en relación al significado de la concepción de Sartre de una dialéctica social inmanente. Por un lado, se supone que Sartre en su Crítica de la razón dialéctica ha adoptado simplemente, en forma servil, una concepción marxista de relaciones sociales. Por otro lado, a veces se supone que su descripción de la dialéctica compleja de relaciones recíprocas entre individuos o grupos, si bien idiosincrásica, es una filosofía existencial social enteramente original. Creo que ninguno de los dos puntos de vista es enteramente correcto. Aun cuando el intento de Sartre para desarrollar las condiciones para la posibilidad de una filosofía social principal con ciertas suposiciones marxistas básicas (por ejemplo, que todas las relaciones sociales se caracterizan por una reciprocidad dinámica, dialéctica, que "el modo de producción de vida material determina, en general, el desarrollo de la vida social, política e intelectual"), ${ }^{1}$ la naturaleza no marxista de su sociología ha sido señalada por los mismos marxistas y por estudiantes de sociología marxista. $^{2}$

A pesar del hecho que Sartre no lo reconoce en su Critica, hay bases para argumentar que los ingredientes esenciales de su noción de procesos sociales, son elementos ligeramente modificados de la sociología existencial de Georges Gurvitch. Se sugerirá que es la teoría sociológica de Gurvitch la que dio forma a los detalles de la concepción de Sartre de la dialéctica social, y que el análisis presentado por Sartre, a pesar de sus intenciones, es un acercamiento útil a los fenómenos sociales que tienen valor para el pensamiento social no marxista.

La concepción de la sociedad como comprendiendo numerosos procesos de interacción, interrelación, conflicto, oposición y reciprocidad, había sido,

1 Jean-Paul Sartre, Critique de la raison dialectique, París, 1960, I, p. 31: "Nosotros nos adherimos sin reserva a esta fórmula de El capital por la que Marx trata de definir su 'materialismo': el 'modo de producción de la vida material domina, en general, el desarrollo de la vida social, politica e intelectual'".

2 Cf. Raymond Aron, Marxism and the Existentialists, Nueva York, 1969, pp. 172-173: "La dialéctica de la serie y el grupo, de la práctica inerte y la praxis revolucionaria, es obviamente sartriana, no marxista. Supone que la acción individual es la única realidad dialéctica y práctica, la fuerza motivo detrás de todo..."

Aron apunta que Sartre parece más interesado en reconciliar una filosofia de destino personal con una filosofía de salvación colectiva, que con los detalles de las teorías socioeconómicas de Marx. Además, se dice que los conceptos mismos de la práctica-inerte, series, conciencia y totalidades, y una dialéctica interminable, son ajenos al pensamiento de Marx o de los marxistas (p. 10). 
por supuesto, sugerida por Hegel y, especialmente en relación a antagonismos de clase, cambio histórico y movimientos sociales, por Marx. En el caso de Hegel, podemos discernir una consideración de una dialéctica inmanente no sólo en la historia humana (concebida como la manifestación, aunque en etapas sucesivas de desarrollo, de lo Absoluto en tiempo), sino en las "contradicciones" en el mundo en realidad (Wirklichkeit). Para Hegel, hay una dialéctica en la experiencia humana así como en los movimientos del pensamiento mismo. Hegel había argumentado que "este proceso dialéctico que la conciencia ejecuta en sí misma —en su conocimiento así como en su objetoen el sentido de que de él, surge el nuevo ... objeto, es precisamente lo que se denomina experiencia." 3 Sin embargo, es claro que en el pensamiento de Hegel todos los procesos dialécticos están finalmente sujetos a una clase de necesidad deductiva que parece privar a los individuos de cualquier libertad real.

Sartre parece concebir la dialéctica social como un proceso contingente que lleva a los individuos en su nisus y, al mismo tiempo, que es sostenido y 'vivido' por individuos en su libre praxis y a través de ella. El movimiento general del pensamiento de Sartre en su Critica parte desde un hincapié sobre el valor heurístico de una interpretación dialéctica de procesos sociales y su naturaleza contingente, hasta una afirmación de la realidad objetiva de una dialéctica inma-nente en sociedad que se caracteriza por necesidad.

Sartre insiste sobre la validez de su propia dialéctica crítica como opuesta a las dialécticas dogmáticas de naturaleza que fueron formuladas por Engels y reiteradas por marxistas dogmáticos.

A este respecto, Sartre sólo expresa un punto de vista previamente adelantado por Georg Lukács. Esto es, que los malos entendidos que surgieron de la comprensión que Engels tenía de las dialécticas

pueden apuntar en lo principal al hecho de que Engels —siguiendo la dirección equivocada de Hegel - extendió el método para aplicarlo a la naturaleza. Sin embargo, las determinantes cruciales de las dialécticas - la interacción de sujeto y objeto, la unidad de teoría y práctica, los cambios históricos en la realidad sosteniendo las categorías como la causa de raíz de los cambios en pensamiento, etc.- están ausentes de nuestro conocimiento de naturaleza. ${ }^{4}$

La relación precisa entre la concepción de Sartre de una dialéctica social y la noción ostensible de Marx de relaciones dialécticas, es una cuestión compleja que me conduciría más allá de los límites de mi interés actual. Sin embargo, puede decirse que la noción de Marx del proceso dia-

3 G. W. F. Hegel, The Phenomenology of Mind, trad. J. B. Ballie, Londres, 1931, "Introducción", p. 142 .

4 Georg Lukacs, History and Class Consciousness, Londres, 1971, p. 24, n. 6. 
léctico de cambio histórico en términos de esfuerzos de clase, no se aplica realmente a la infraestructura de los procesos sociales. El caso claro en que Marx pareció emplear una interpretación puramente dialéctica de los eventos históricos, se encuentra en El dieciocho Brumario de Luis Napoleón Bonaparte. En sus obras posteriores —especialmente El capital - tendió a destacar factores causales subyacentes en un tipo de noción unidimensional de causación histórico-social. A pesar de la plétora de referencias al "método dialéctico de Marx", es curioso que haya una escasez de evidencia textual para indicar la naturaleza o uso de ese método. ${ }^{5}$ No importa lo que uno pueda pensar sobre los detalles precisos de los análisis dialécticos de Marx, es claro que Sartre creyó que sus propias descripciones de los fenómenos sociales eran una extensión y amplificación del acercamiento de Marx a dichos fenómenos.

Con obvia aprobación, Sartre se refiere a El dieciocho Brumario como una "síntesis difícil de intención y resultado" que es en mucho superior a los recientes análisis marxistas de procesos histórico-sociales. ${ }^{6}$ Hay poca duda de que Sartre supone seguir las pisadas de Marx en su desarrollo de una

5 Casi todos los comentaristas del pensamiento de Marx hacen referencia a su "método dialéctico" o su "entendimiento dialéctico de los fenómenos sociohistóricos", a pesar del hecho de que no se hace ningún intento para establecer precisamente a qué se refieren estas observaciones en los trabajos de Marx. En un estudio reciente del pensamiento de Marx, hay una discusión de "Las dialécticas de cambio" que indican el uso de Marx de la terminología dialéctica en su interpretación del supuesto desarrollo interno del modo capitalista de producción. En El capital, se dice que los modos capitalistas de producción crean la propiedad privada capitalista. Esto, a su vez, niega la propiedad privada individual. El productor adquiere propiedad individual sobre la base de las adquisiciones de un perfodo capitalista y, por lo tanto, la producción capitalista inicia una "negación de la negación" (Capital, Moscú, 1965, I, p. $7^{6} 3$ ). Al discutir la ostensible abolición del sistema capitalista de producción, Marx usa el término hegeliano Aufhebung que implica la negación y preservación de ese sistema en un proceso de transición (Capital, III, pp. 427-429). Lo que se muestra en estas referencias al uso de Marx del análisis dialéctico, es que está, en su mayor parte, restringido a su entendimiento del proceso interno de la transformación del capitalismo. Cf. Shlomo Avineri, The Social and Political Thought of Karl Marx, Cambridge, 1970 , pp. 174-184. Sartre mismo se refiere a una observación ambigua de Marx en su segundo prefacio a El capital. En respuesta a una reseña de la obra en el Courrier Européen, Marx dice que quien hizo la reseña ha dado una buena relación de su método, pero la cuestión de el método dialéctico, permanece abierta. J. P. Sartre, Critique de la raison dialectique, p. 6o. Hay poca duda de que Marx sí hace uso de un método dialéctico de interpretación en su análisis del desarrollo del capitalismo (como él lo entiende), pero hay poca evidencia de que adopte una concepción universal de dialéctica social a la que apele uniformemente en sus estudios.

En un reciente estudio del pensamiento de Marx, se expresó una opinión anómala acerca de la relación entre Sartre y Marx. Se ha dicho que "El existencialismo puede ... desempeñar la parte de un correctivo a la ortodoxia del Soviet del día de hoy, restaurando el crédito de una subjetividad largamente suprimida en su concepción de dialéctica objetivamente restringida ... El modo de argumento de Sartre no se basa exclusivamente en su doctrina existencialista. sino también en las posiciones que se habian alcanzado dentro del marco del marxismo en si, hace mucho tiempo". Alfred Schmidt, The Concept of Nature in Marx, Nueva York, 1972, p. 166.

6 CRD, p. 38. 
descripción concreta de praxis individual, la transformación del mundo mediante la superación de condiciones limitantes existentes, la reciprocidad entre hombre y hombre y entre grupo y grupo, la dialéctica de lo subjetivo y lo objetivo, y el conflicto que expresa el carácter universal de clase y condición. Los pensadores marxistas, por otro lado, comúnmente han convenido que hay poco en la Critica de Sartre que se asemeje a los principios sociológicos de Marx o sus análisis. Queda todavía la cuestión de si la filosofía social de Sartre es enteramente única o idiosincrásica.

El desarrollo de una dialéctica social en el pensamiento de Sartre, es algo que emergió fuera de un contexto en el cual ya Georges Gurvitch y otros habían desarrollado una sociología dialéctica madura. Aunque la relación entre la filosofía social de Sartre y la sociología de Gurvitch se ha notado ocasionalmente, hasta donde yo sé no se ha hecho ningún esfuerzo para ver si esta relación es sustancial o mínima. Se hará un intento para mostrar que algunas de las concepciones centrales de Gurvitch proporcionan una introducción clara al lenguaje y forma del entendimiento de Sartre de la sociedad y las relaciones complejas que comprende. Aunque Sartre no sigue la descripción de Gurvitch de la dialéctica social en cada detalle, la orientación general a los fenómenos sociales adoptados en la Crítica de Sartre claramente está en deuda con el esquema de la forma de relaciones sociales de Gurvitch.

\section{Determinismo social y libertad humana}

En El ser y la nada, Sartre había sostenido que el mundo se caracteriza por una estructura determinista, que el mundo natural está dominado por un sistema de relaciones causales que es ajeno a la libertad humana. Sin embargo, habia argumentado que el significado y la significación (meaning and significance) de facticidades en el mundo, es relativo a la intensionalidad de conciencia proyectiva (el pour-soi). Se había afirmado que la conciencia subjetiva, en situación, se encuentra "comprometida en ser", "rodeada por el ser", "amenazada por el ser", o encuentra la Selbständigkeit ("independencia") de las cosas en el mundo. La condición de la autoconciencia individual parece ser diferente en relación a las relaciones humanas hasta donde otros se descubren como seres conscientes ajenos, cuyos proyectos pueden estar en conflicto con los propios. Esta condición de la "realidad enajenante del otro", encuentra expresión en la noción de Sartre del coeficiente de adversidad que es puramente humano. La relación entre uno mismo y otros, como la describe Sartre, es seguramente una de las bases para una comprensión dialéctica de las relaciones entre individuos y otros individuos, individuo y grupo, y grupos opuestos?

7 La relación dialéctica entre yo y otros, interioridad y exterioridad, etc., había sido 
Sin embargo, la concepción explícita de una sociología dialéctica es, principalmente, una respuesta al pensamiento marxista en Francia, por parte de sociólogos como Gurvitch. En lo que Sartre había tocado sobre la existencia del hombre en el mundo de otros en las porciones concluyentes de su análisis de relaciones concretas con otros, había preparado los cimientos para una fenomenología social en su ontología existencial. Específicamente, las cuestiones suscitadas en relación con la acción humana concreta en situación, parecieron clamar por una extensión al mundo social. Así, cuando Sartre asegura que

actuar es modificar la forma del mundo .. arreglar medios en vista de un fin ... producir un complejo instrumental organizado tal que, mediante una serie de concatenaciones y conexiones, la modificación efectuada en uno de los eslabones cause modificaciones a través de toda la serie y, finalmente, produzca un resultado anticipado, ${ }^{8}$

parecemos carecer (en El ser y la nada) de la estructura social en la cual tal acción podría tener lugar y carecemos de cualquier consideración de otros como agentes sociales. Permanece la cuestión de si hay factores cooperativos - limitativos significantes, implicados en la acción social en relación a la existencia de otros. Nos gustaría saber la forma o estructura de relaciones con otros en un campo social y en uno práctico. Además, el problema de la naturaleza de un posible determinismo social (como algo distinto de un determinismo natural), siguió sin resolver en la fenomenología existencial de Sartre. Estos son precisamente los tipos de problemas en los que se interesaba Gurvitch en Los determinismos sociales y la libertad humana.

A pesar de que, en general, Gurvitch adopta un método dialéctico de interpretación de los fenómenos sociales, admite que hay una "pluralidad de determinismos sociales" que son parciales y sujetos a la intervención de la libertad individual. En las expresiones individuales y colectivas de la vida social, la libertad es posible y es el origen fundamental de lo inesperado o impredecible. Ciertamente, esta libertad individual no es una libertad abstracta; más bien se expresa en una matriz compleja de relaciones recíprocas entre individuo e individuo, "el otro" y "nosotros", y las

discernida en L'Ontologie de Sartre de G. Varet (París, 1948), ya que Varet argumentó que hay una dialéctica de la relación en la fenomenología de Sartre (p. 173). Además, se sugiere que la dialéctica ontológica implícita en $E l$ ser y la nada no es una dialéctica abstracta, sino una clase de empirismo dialéctico (op. cit., pp. 163-179). Más recientemente se ha discutido que la ontología de Sartre del encuentro con "el otro", es una "dialéctica" que incluye una "reciprocidad alternante del encuentro" entre el yo y el otro. Klaus Hartmann, Sartre's Ontology, Evanston, 1966, p. 124. Un intento para mostrar la continuidad entre la explicación de Sartre de la relación entre el yo y el otro en El ser y la nada y la Critica, se presenta en un estudio reciente de la filosofía social de Sartre. Cf. Klaus Hartmann, Sartres Sozialphilosophie, Berlín, 1966, p. 26 ss.

$8 \mathrm{~J}$. P. Sartre, L'Etre et le néant, Paris, 1943, p. $5^{08 .}$ 
clases sociales dominantes. En la medida en que Gurvitch tenía sensibilidad para los problemas filosóficos en sociología, estaba interesado en el "ser" de realidad social y una ontología de fenómenos sociales. Para entender la infraestructura de este modo de ser, se asumía que las relaciones sociales humanas son a menudo "paradójicas" y que la sociedad no puede ser entendida aparte de la comprensión de la relación dialéctica entre el individuo y la colectividad, la realidad social parcial y la global. La forma más primitiva de rapport social, se refiere a las relaciones del "yo", el "alter ego" y "nosotros". La multiplicidad de los fenómenos sociales. así como su manifestación multidimensional, se describe en términos de esta interrelación fundamental. Esta interrelación se expresa en las situaciones sociales reales, por virtud de "polarización", "ambigüedad", "complementaridad" y una "reciprocidad de perspectivas". Un todo social o "totalidad", de acuerdo a Gurvitch,

representa en su esencia un móvil ... sistema concreto de equilibrio basado en una fusión de "perspectivas recíprocas", un sistema que es dinámico y donde los elementos irreductibles de multiplicidad y unidad, individual y universal, tienden a ser sintetizados en una forma que es perpetuamente cambiante. ${ }^{9}$

Aunque Gurvitch acepta el ideal de la posibilidad de coordinación, integración y cooperación, con mucha menos renuencia que Sartre, también se da cuenta de que el entrejuego dialéctico de los proyectos de individuos y otros, grupos y contragrupos, a menudo se caracteriza por un antagonismo recíproco. Se asume que el acceso metodológico primario a los fenomenos sociales complejos, no es el 'sociologismo' objetivista de Durkheim (para quien los hechos sociales son cosas) ${ }^{10}$ o el "empirismo abstracto" de la sociología americana (por ejemplo, el estructuralismo analítico de Talcott Parsons); sino más bien el método propio en la investigación sociológica es un método dialéctico de interpretar y describir los fenómenos y procesos sociales.

Como opuesto al modelo analítico, causal, de los dominantes sociólogos norteamericanos [que Sartre caracteriza como "sociologia burguesa"], Gurvitch propone una concepción de "el ritmo de realidad social" que abarcará

9 Georges Gurvitch, L'Idèe du droit social, París, 1932, p. 17.

10 Emile Durkheim había sostenido que los hechos sociales deben ser considerados como cosas, como datos independientes del sujeto que conoce. Se supuso que los fenómenos sociales pueden ser estudiados por emulación de los métodos de las ciencias físicas. Cf. Emile Durkheim, Les Règles de la méthode sociologique, París, 1950, p. ${ }_{15}$, p. 27 ss. Cf. también, Emile Durkheim, L'Ẽolution pèdagogique en France, París, 1938, II, p. 217; "Es necesario observar (la realidad humana) como uno observa las cosas del mundo externo, por así decirlo, desde afuera; es necesario experimentar, inducir, o si la experimentación es imposible físicamente, uno debe encontrar los medios de instituir comparaciones objetivas que puedan llenar la misma función lógica". 
la destructuración así como la estructuración, la microsociología tanto como la macrosociología, los grupos estructurados sin cohesión así como las clases sociales relativamente estables. La bifurcación de individuos y colectividad se considera una falsa noción, por cuanto ignora la interdependencia mutua del individuo y la sociedad. La relación dialéctica entre individuos y otros no se considera como una afirmación conceptual importada a los análisis sociales; más bien se sostiene que dicha relación es "inmanente" en los procesos sociales reales. Los fenómenos socio-culturales (por ejemplo, instituciones o símbolos culturales), son creados por el entrejuego dialéctico individual, interpersonal y colectivo. Como si estuviera explícitamente atacando el primer existencialismo de Sartre, Gurvitch critica el concepto del "yo puro" que existe en autonomía completa aparte de todas las relaciones sociales concretas. Mientras sostiene que el individuo es único y contribuye un factor subjetivo a los procesos sociales, Gurvitch insiste también en que el individuo llega a ser un individuo en un medio social que necesariamente influye sobre su existencia personal. Un individuo concebido como absolutamente independiente de otros, es una persona abstracta, sin ninguna existencia real. En este respecto, Gurvitch sostiene que “... los patrones sociales guian y dirigen no solamente el comportamiento, sino también la vida mental misma, ya sea colectiva o individual". ${ }^{11}$

En contraste con el punto de vista general marxista de que los papeles sociales expresan membrecía de clase, Gurvitch se refiere a la interpenetración de dichos papeles y su contribución a procesos de "estructuración" y "destructuración". Los papeles sociales se describen como los trampolines para las posibles acciones individuales o colectivas. ${ }^{12}$ Estas dimensiones sociales del individuo no se consideran como características contingentes anónimas de personas, sino como medios por los cuales un individuo (o grupo) expresa libertad en una matriz social. Porque es la totalidad social la que determina la viabilidad de la "trama de los papeles sociales" y es un factor determinante que afecta las limitaciones de la libertad concreta. Como en el caso de la descripción de los procesos sociales de Sartre, Gurvitch no asume una separación radical de sociología propia y psicología social, por cuanto el dominio de los fenómenos sociales totales traslapa las motivaciones psicológicas de individuos y grupos. En relación a este problema, es interesante notar que los papeles sociales o funciones desempeñan un papel significativo en la fenomenología social de Sartre, en comparación a su menosprecio de dichos papeles en El ser y la nada. En la Critica, Sartre parece estar de acuerdo con el punto de vista general de Gurvitch de que la acción humana se expresa a través de una variedad de papeles sociales. La situación descrita en la Crítica en la cual un "veraneante" (Sartre) observa

11 Georges Gurvitch, La vocation actuelle de la sociologie, Parls, 1950, I, pp. 73-74. 12 Ibid., pp. 80-81. 
en su trabajo a un trabajador de la construcción y un jardinero, claramente indica este cambio de hincapié. Porque se dice que los otros son vistos como agentes sociales cuyas acciones diferentes son desconocidas mutuamente, aunque observadas por un estivant. Esta situación se caracteriza como una en que el observador de los trabajadores los designa como 'otro' (por ejemplo, como pertenecientes a otra clase, otra profesión, etc.) y, por "interiorizar esta designación", el observador entra en un dominio objetivo en el cual "estas dos personas realizan su mutua dependencia más allá" del observador. ${ }^{13}$

Una diferencia significativa entre Sartre y Gurvitch, es que el primero no acepta la noción del último de que hay una "psique colectiva"14 que es, supuestamente, algo sobre y por encima de los individuos como seres psicológicos. A este respecto, Sartre argumenta explícitamente que no hay conciencia colectiva misteriosa que emerja de la solidificación de grupo, ${ }^{15}$ aun cuando él mismo sí supone que en los grupos organizados motivados por un "interés común" o una "necesidad común", hay lo que describe como una "conciencia común" (conscience commune). Sin embargo, en otros respectos, Sartre parece aceptar el hincapié de Gurvitch sobre el traslape de la sociología y la psicología social, la variabilidad de los papeles sociales en una estructura social significativa, las determinaciones reales que se encuentran en la acción social y, por supuesto, la concepción central de una dialéctica inmanente en las totalidades sociales.

La complejidad de la realidad social se manifiesta primariamente en lo que Gurvitch describe como "microsociología"- esto es, la dimensión de "electrones sociales" o aquellas relaciones individuales con otros que al principio se relacionan vagamente con una unidad social más extensa (el gruponosotros). El alcance de la intensidad de estas relaciones (en coordinación con otros vínculos sociales), se representa como un continuo que se extiende desde una "fusión parcial" del individuo hasta comunión societal, o esa forma ideal de integración social en la cual se abroga el conflicto. Dichos vínculos sociales se edifican, en esencia, sobre relaciones sociales elementales que constribuyen ya sea a la creación de estructuras sociales o a su desinte-

$13 C R D$, p. 184. Al establecer la etapa para esta descripción de una situación social concreta, Sartre vuelve atrás sobre su descripción de la relación entre el yo y el otro en términos que habla usado previamente en El ser y la nada. Así, observa que "Ia realidad de el otro me afecta en lo más profundo de mi existencia, en tanto que esa realidad no es mi realidad". Ibid., p. 183 .

14 Georges Gurvitch, The Spectrum of Social Time, trad. M. Korenbaum y P. Bosserman, Dordrecht, Holanda, 1964 , p. 5 .

$15 C R D$, p. 507. Sartre desea evitar toda interpretación mágica o mística de grupos. La ubicuidad de grupos en acción es una determinación práctica de cada individuo a través de cada individuo, de todos, en la perspectiva de una praxis común. La suposición de que una conciencia común puede ser atribuida a un grupo en acción, es algo ambigua en la relación de Sartre, aun cuando parece claro que no pretende que esta noción es equivalente al concepto de "psique colectiva" o "conciencia colectiva". 
gración ("destructuración"). Como en los análisis de grupos sociales de Sartre, las unidades sociales consistentes de relaciones elementales son agrupaciones de hecho (que corresponden a la serialité de Sartre), agrupaciones impuestas (correspondientes a la descripción de Sartre de grupos que constituyen otros grupos como grupos), y asociaciones voluntarias. Las relaciones de individuos dentro de estos tipos de grupos y las relaciones entre grupos, se caracterizan como dialécticas. Una sociología "profunda" o multidimensional, entiende la realidad social como

arreglada en niveles, estratos, planos o en capas. Estos estratos, o niveles, se interpenetran o impregnan mutuamente unos a otros. A mayor abundamiento, no cesan de entrar en conflicto: su comunicación (rapport) es tenue, paradójica y dialéctica. Esto tiene que ver con las intricadas tensiones inherentes en toda realidad social.16

Gran parte del material que trata con grupo-formaciones, con las tensiones dentro de los grupos y entre grupos, encontrará en la "sociología existencial" de Gurvitch su camino a la fenomenología de Sartre de la dialéctica de grupo-formación.

La dinámica de la realidad social, como se expresa en las diversas dimensiones de la existencia social, requiere una interpretación dialéctica apropiada a la actividad social y al movimiento real inmanente en la mulplicidad de las relaciones sociales. La sociedad como un todo se concibe como una totalidad dinámica que Gurvitch ( y Sartre después de él) cree que es inteligible, aun cuando no completamente accesible a los análisis racionalistas o lógicos de los fenómenos sociales. Ciertamente, la razón y la lógica desempeñan un papel significativo en la construcción teórica y la categorización de ciertos aspectos de la realidad social; pero un acercamiento racionalista a los fenómenos sociales tiende a generar modelos estáticos, objetivos, de dichos fenómenos, como también a cristalizar o simplificar la realidad vivida de la existencia social. Una dialéctica social debería enfocar las sinuosidades, flexibilidades y tensiones perpetuamente renovadas de la vida social, en sus dimensiones vertical y horizontal. La orientación de la mayoría de los sociólogos empiristas norteamericanos, tiende a ser en la dirección de reduccionismo, objetivación, sobrehincapié de la estructura y la cuantificación de los fenómenos sociales vitales. Un acercamiento dialéctico a los fenómenos sociales impide el establecimiento de absolutos y destaca la fluidez y las características siempre cambiantes de la realidad social. Porque tanto para Gurvitch como Sartre, el observador sociológico no tiene un punto de ventaja objetivo, privilegiado, desde donde él describe los procesos sociales, en tanto está comprometido (engagé) en la realidad social que

16 Georges Gurvitch, La vocation actuelle de la sociologie, I, p. 63. 
describe. Gurvitch sostiene, contra el "empirismo abstracto" de la sociología norteamericana, que un método dialéctico hace más o menos accesibles las variedades de la existencia social, así como los fenómenos inesperados o no anticipados que podrían ser descartados por los sociólogos empiristas como anomalias.

En relación con la sociología norteamericana, Sartre observa que es una forma de "hiperempirismo" que descansa sobre fundamentos teóricos inestables. Sartre argumenta que los sociólogos como Lewin presentan una "síntesis de externalidad" que convierte una "totalización en proceso" en totalidades fijas. En el empirismo de la sociología norteamericana, hay un interés en "poner al sociólogo fuera del campo experimental", para crear un objetivismo artificial. ${ }^{17}$ El punto de vista de Sartre a este respecto, es que un hiperempirismo que fue sintetizado con una concepción dialéctica de la interrelación de lo subjetivo y lo objetivo, la interioridad y la exterioridad, y un sentido de los factores históricos que contribuyen a la direccionalidad de los procesos sociales, podría ser considerado como un momento o etapa "en el movimiento de la totalización histórica". Dicha síntesis podría producir una

sociología que mantendrá la relativa irreductibilidad de los campos sociales, que pondrá de manifiesto - en el corazón del movimiento general- las resistencias, los impedimentos, las ambigüedades, las incertidumbres ... El desarrollo mismo de la filosofía dialéctica debe conducirla a producir - en un solo acto- la síntesis horizontal y la totalidad a fondo. ${ }^{18}$

Que la incorporación de lo que es valioso en el hiperempirismo en una sociología dialéctica es pertinente al pensamiento social de Sartre, resulta claro en su sola referencia a Gurvitch. Al introducir su concepción de una dialéctica crítica, Sartre se refiere a los métodos variables usados por Georges Lefebvre en La Revolución Francesa (París, 1930-1957). Obviamente impresionado con la noción de Lefebvre de que la historia no es una cosa, sino que obedece a diversas leyes, Sartre observa que Lefebvre muestra que los aparentes "factores independientes" en un proceso histórico, tienden a conducir a un evento que se desarrolla de acuerdo con el esquema de totalizar individuos o grupos. Sartre está de acuerdo con la designación de Gurvitch de un acercamiento tal al entendimiento históricosocial, como una forma de "hiperempirismo dialéctico". Este método (que es el que Sartre cree usar en la Crítica) se apropia sin prejuicio los varios tipos de racionalidad que se encuentran en una investigación. Esto es, uno debe atender al objeto de una investigación en sí, porque se da a sí y se permite desarrollar

$17 C R D$, p. 52 .

18 Ibid., p. 58. 
libremente ante los ojos de uno. Un hiperempirismo dialéctico considera los "movimientos totalizantes", "la reciprocidad de condiciones" y las varias "perspectivas", que se encuentran a sí mismas en las experiencias pasadas y se verifican a sí mismos en el curso o la experiencia presente. El valor de dicho método es que a veces descubre campos dialécticos, a veces determinismos analíticos y, en algunos otros casos, se acerca a los fenómenos usando otro modo de racionalidad. ${ }^{19}$ Esta caracterización de la forma en la cual uno desarrolla una "antropología empírica" es compatible, mutatis mutandis, con la concepción de Gurvitch de una "sociología existencial".

Que así es, se ilustra en la noción de Gurvitch de los determinismos parciales que son limitados, relativos y sujetos a factores "diacrónicos" (o cambiantes, duracionales). El determinismo que se admite como pertinente a la realidad social (como sucede con el hiperempirismo dialéctico que Sartre menciona), no es un determinismo universal aplicable a todos los fenómenos. Como Gurvitch lo expresa,

determinismo es la integración de hechos particulares en una de las estructuras reales, múltiples, o universos concretos (reales, conocidos o construidos) que siempre permanece contingente; ... sitúa estos hechos, esto es, los explica en relación a su entendimiento de la relativa cohesión de la estructura contingente en cuestión, además de desplegar la vida dentro de una o varias de las temporalidades. ${ }^{20}$

Esta concepción general de la cohesión de una estructura que es en sí contingente, proporciona una noción limitada de determinación social que no niega en lo absoluto la libertad humana, sino que estipula las limitaciones de esta libertad en situaciones sociales particulares. Es claro que el "semideterminismo" descrito en la crítica de Sartre de una dialéctica racional, debe mucho a la concepción de los "determinismos parciales" de Gurvitch. Sin embargo, debe hacerse notar que Sartre no argumenta que cuando el hombre entra en las relaciones sociales o llega a ser un miembro de un grupo, renuncia por completo a su libertad existencial. Porque se dice que el hombre no es dominado por el determinismo social, en tanto "no es no libre" en la acción social. Esto es, el hombre ha de ser un individuo libre para poder captar los significados de las cosas y ejecutar los mandatos que ellos implican.21 Aunque ésta parece ser una noción bastante negativa de la libertad, no es incongruente con la descripción de Sartre de la libertad concreta en situación, en El ser y la nada. Lo que Sartre admite es que la

19 Ibid., p. 117. En la Sartres Sozialphilosophie de Klaus Hartmann (Berlín, 1966), se anota erróneamente que la única referencia de Sartre a Gurvitch está en la p. 190. Cf. K. Hartmann, Sartres Sozialphilosophie, p. 57 .

20 Georges Gurvitch, Déterminismes sociaux et liberté humaine,' París, 1955, p. 40.

21 Cf. Walter Odajnyk, Marxism and Existentialism, Nueva York, 1965, p. 149. 
intervención de la libre praxis de un individuo en un proceso social, sujeta al individuo a determinismos parciales que circunscriben su libertad. Si a algo tiende Sartre en su fenomenología concluyente de grupo-formación, es a introducir una noción de necesidad que no se justifica por la descripción de Gurvitch del hombre en sociedad. De hecho, se podría argumentar que la admisión de Sartre de una necesidad ostensible en la dialéctica social, es un rasgo paradójico de su fenomenología social que mina su intención de preservar al individuo libre dentro de la estructura de los procesos sociales.22

Los determinismos parciales no sólo son factores limitativos que circunscriben la libertad del hombre en la existencia social, sino que la relativa estabilidad de los fenómenos concretos totales manifestados en "el nosotros" o en grupos y clases, en sí se relaciona a las estructuras globales sociales en larga escala que pueden penetrar los grupos relativamente más pequeños. Estas estructuras globales (reveladas en las relaciones internacionales, por ejemplo) traen a las organizaciones sociales dentro del dominio de la historia. Como Sartre en su Critica, Gurvitch avizora una serie de círculos circundantes que traslapan la vida social del individuo, conduciendo hacia fuera al círculo de las fuerzas históricas que dominan una etapa particular de la historia humana. En este sentido, no hay bifurcación radical entre sociología e historia; más bien, hay un continuo que circunda a las dos. Como Sartre dirá en su discusión de "el grupo en la historia", el movimiento de la Historia es una relación dialéctica recíproca a la praxis humana en grupos organizados. Sartre se refiere a esta relación en sus observaciones finales en la Critica, al argumentar que debe haber una posible progresión sintética que comprende ambos movimientos, sincrónicos y diacrónicos, por los cuales la historia se "totaliza" a sí misma, incesantemente. ${ }^{23} \mathrm{Si}$ bien es de dudar que haya revelado el profundo significado de la historia, su intento total para relacionar una descripción de las formas de la experiencia social del hombre al "movimiento de la historia", está en el espíritu del proyecto general sociológico de Gurvitch. Ciertamente Sartre parece adoptar, in toto, el punto de vista de Gurvitch que tanto la historia como la sociología tratan con "todos los fenómenos sociales". Aunque hay un buen número de variaciones sobre los temas de Gurvitch en la fenomenología social de Sartre, no divergen demasiado de la orientación central de la sociología dialéctica del primero. Esto es especialmente cierto en relación al deseo de preservar la libertad del individuo dentro de un contexto social en el cual emergen factores deterministas parciales y contingentes. La concepción de Gurvitch

22 Cf. George J. Stack, "Sartre's Social Phenomenology", Studium Generale, 22 (1969), pp. 1006-1008. En este ensayo yo habia sugerido, en un punto, que parece que Sartre cae gradualmente bajo la fascinación de una concepción hegeliana de los procesos dialécticos. ya que los describe como necesarios. Además, se habia discutido que Sartre ofrece una interpretación hiperracionalista del desarrollo de los grupos y de su acción.

23 CRD, pp. $754-755$. 
del posible surgir de lo inesperado o la aparición de cambio radical en sociedades, es muy evidente en la relación de Sartre del papel del individuo en la praxis de grupo. Gurvitch, en La vocación actual de la sociología, crea un retrato de la erupción dinámica de la "libertad creadora", que se reiterará en la descripción de la dialéctica social de Sartre. Sintetizando muchas de sus nociones básicas, Gurvitch afirma que

uno encuentra en todos los fenómenos sociales como se expresan en ... estructuras macrosociológicas ... factores que conducen a cambio radical: es la ... prueba de fuego de ... los "medios difusos" . . . los instantes fugitivos de la vida social, donde los grupos, las sociedades, la humanidad, realizan una conciencia de sí mismos ... fuera de lo esperado, lo predecible, lo anticipado ... es el ... elemento inesperado, ... imprevisto, discontinuo ... e inseparable de una totalidad en marcha. Esta totalidad es donde ... el acto, la libertad inventiva, la libertad de tomar decisiones, y la libertad creadora, causan una erupción en la vida social más allá de todo lo previsto. Dichos fenómenos ... subsisten en todos los fenómenos sociales, sean globales o parciales, macrosociológicos o microsociológicos ... A este reespecto, cada estructura ... es un tributario de todos los fenómenos sociales como tales, a los cuales trasciende. ${ }^{24}$

Sartre, como Gurvitch, procede de lo microsociológico a lo macrosociológico, y concibe la sociedad como tal como una "totalidad en marcha". Sartre sigue la dirección de Gurvitch, sosteniendo que el individuo es el elemento de lo intencional (locus of intentional), acción originadora y un mediador de las fuerzas sociales y materiales que actúan sobre él y circunscriben su libertad de acción. Al explicar el proceso del movimiento dialéctico, Sartre reclama que es la "ley de totalización" (la loi de totalisation) la que crea colectividades, sociedades y una historia. Estas realidades se imponen a sí mismas sobre el individuo, pero al mismo tiempo, están "entretejidas por millones de actos individuales". ${ }^{25}$ Lo que Sartre trata de indicar aquí es que hay una tensión entre la sumisión del hombre a un movimiento dialéctico del cual él es el elemento, y su capacidad de contribuir a este movimiento. Resulta claro de la observación de Sartre que esta situación se propone como paradójica y que "el hombre suire lo dialéctico en tanto lo hace, y lo hace en tanto está sujeto a ello". ${ }^{26}$

Sin referencia específica a lo que entiende Gurvitch por dialética social, Sartre describe los procesos de acción y reacción, libertad individual y obje-

24 Georges Gurvitch, La vocation actuelle de la sociologie, I, pp. 438-439.

25 J. P. Sartre, op. cit., p. 191.

26 Ibid. Se argumenta que "en un cierto sentido ... el hombre sufre la dialéctica como un poder enemigo y en otro sentido la hace ... lo que significa que el hombre sufre la dialéctica en tanto que la hace, y que la hace en tanto que la sufre". 
tiva, factores determinados que tropiezan en esa libertad en el lenguaje de la sociologia de Gurvitch. Los siguientes temas específicos parecen tener mucha influencia en el pensamiento de Sartre: a) el hincapié sobre la naturaleza dialéctica de la experiencia social 'vivida'; $b$ ) la interacción entre individuo y grupo; $c$ ) la noción de una "reciprocidad de perspectivas"; $d$ ) la concepción ontológica de personas individuales, grupos y "todos los fenómenos sociales"; e) el intento de comprender la historia de la vida de los grupos sociales desde el punto de vista de su ser; ${ }^{27} f$ ) la espontaneidad de la praxis creadora, individual; $g$ ) la comprensión de todos los fenómenos sociales dentro de un marco histórico-social; $h$ ) la interpenetración de las dimensiones verticales y horizontales de la realidad social; $i$ ) la suposición de la complementaridad del observador social y el fenómeno observado; ${ }^{28}$ j) lo inadecuado de las teorías estáticas y objetivas de los "empiristas abstractos" norteamericanos; $k$ ) el concepto de sociedad como una totalización en cours; $l$ ) y el interés por la condición humana o la dimensión existencial de la vida social. Luego, en relación a un número de puntos especificos, hay una fuerte analogía entre la "sociologia existencial" de Gurvitch y la fenomenología social de Sartre.

Para mi, fue la sociologia de Gurvitch la que sugirió a Sartre la posibilidad de desarrollar una fenomenología social postmarxista ${ }^{29}$ que pudiera incorporar los principios básicos de la sociología de Marx y evitar el marxismo dogmático. Lo que Sartre describe como la "lógica viviente de la dialéctica", había sido ya discernido por Gurvitch, ya que él insistió sobre "la notable afinidad que existe entre la dialéctica como ... un método, como un movimiento real, y la experiencia". ${ }^{30}$ Desde el punto de vista de Gurvitch, es el "factor humano", o la condición existencial del hombre, lo que es la base de los procesos dialécticos, y no una fuerza impersonal, metafísica, inmanente, en la sociedad y la naturaleza. La concepción de Gurvitch de la "dialéctica de complementaridad" que caracteriza la vida social y la observación social, encuentra un lugar significativo en la Crítica de Sartre, en cuanto la adopta como la teoría de conocimiento. Como Sartre lo dice,

la reflexión ... es un punto de partida sólo si nos arroja de vuelta inmediatamente entre las cosas y los hombres, en el mundo. La única teoría de conocimiento que puede ser válida hoy, es una que esté fun-

27 Cf. P. Bosserman, Dialectical Sociology, Boston, 1968, p. 283.

28 Cf. $C R D$, p. 3o, n. I.

29 George Lichtheim se refiere a Georges Gurvitch como un "empirista liberal", cuyos estudios sociológicos se dieron en la corriente francesa de pensamiento postmarxista. Cf. Márxism in Modern France, Nueva York y Londres, 1966, pp. 83, 106.

30 Georges Gurvitch, Dialectique et sociologie, París, 1962, p. 181. Cf. J. P. Sartre, Critique de la raison dialectique, p. 119: "La dialéctica es un método $y$ un movimiento en el objeto; se funda ... sobre una afirmación de base que concierne a la vez a la estructura de lo real y de nuestra praxis". 
dada en esa verdad de la microfísica: el experimentador es una parte del sistema experimental ... la revelación de una situación se efectúa en la praxis que la cambia y a través de ella. ${ }^{31}$

Además de esta aparente apropiación de la "dialéctica de complementaridad" de Gurvitch (que se deriva de los problemas metodológicos en microfísica), hay un sentido en el cual la adopción de Sartre de una forma de comprehensión que, más o menos, corresponde a la concepción de Dilthey y Weber de Verstehen, se relaciona a un aspecto del pensamiento de Gurvitch, Porque Gurvitch presenta una concepción de comprehensión que parece tener su eco en la Critica de Sartre. Dice que

es tan imposible explicar sin comprender la estructura, como comprehender la relativa coherencia de esta última sin llegar a alguna conclusión sobre la manera de integración, que es explicación. ${ }^{32}$

Quizá la comparación más significativa entre la fenomenología social de Sartre y la sociología de Gurvitch, se encuentra en la noción general de que hay "determinismos parciales" que emergen en los procesos dialécticos sociales (una noción que parece estar presente en la admisión que hace Sartre de factores limitantes que restringen la libertad individual). En la concepción de Sartre del trabajo humano como una "relación entre hombres" y "una relación de hombre al mundo material", se sostiene que hay determinaciones sintéticas y un "círculo de condiciones" que circunscribe la libertad individual en una etapa particular de la dialéctica de la praxis. ${ }^{33}$ Parecería que también Sartre ha introducido una concepción de determinismos parciales contingentes a su descripción general de la interacción de subjetividad y objetividad en el campo social. De hecho, podría decirse que la síntesis o interacción de la libertad individual y la objetividad socio-material, es el tema central de la Crítica de la razón dialéctica, que es un tema implícito en la sociología existencial de Gurvitch. Ciertamente podemos discernir en la compleja descripción de Sartre de, la dialéctica de la praxis _la acción y reacción, el movimiento y contramovimiento, la repercusión de "asunto trabajado" sobre la libertad de los agentes sociales, etc.- una concepción de existencia social que descansa en el corazón de cualquier modo dialéctico de interpretar los fenómenos y procesos sociales. Si la dialéctica social que Sartre describe no es una apropiación literal de los principios y concepciones básicos adelantados por Gurvitch, por lo menos parece estar en deuda con la "dialéctica hiperempírica" de este último, en espíritu e intención. Si hay algu-

31 CRD, p. 30, n 1.

32 Georges Gurvitch, Déterminismes sociaux et liberté humaine, p. 40. Cf. J. P. Sartre, $C R D$, p. 96.

33 CRD, p. 174 . 
na validez en las analogías que he tratado de trazar entre varios aspectos de la fenomenología social de Sartre y la sociología de Gurvitch, resultan muy dudosas las suposiciones de que Sartre ha creado una teoría social idiosincrásica, cuasi-marxista, o que ha intentado construir una síntesis imposible de existencialismo y sociología marxista.

George J. Stack

(Trad. de Rolando Gutiérrez Cortés)

Department of Philosophy

S. U. N. Y. AT BROCKPORT 